\title{
Gender and the business cycle: an analysis of labour markets in the US and UK
}

Article

Accepted Version

Razzu, G. and Singleton, C. (2016) Gender and the business cycle: an analysis of labour markets in the US and UK. Journal of Macroeconomics, 47. pp. 131-146. ISSN 0164-0704 doi: https://doi.org/10.1016/j.jmacro.2015.12.006 Available at https://centaur.reading.ac.uk/51709/

It is advisable to refer to the publisher's version if you intend to cite from the work. See Guidance on citing.

To link to this article DOI: http://dx.doi.org/10.1016/j.jmacro.2015.12.006

Publisher: Elsevier

All outputs in CentAUR are protected by Intellectual Property Rights law, including copyright law. Copyright and IPR is retained by the creators or other copyright holders. Terms and conditions for use of this material are defined in the End User Agreement.

$\underline{\text { www.reading.ac.uk/centaur }}$

\section{CentAUR}


Central Archive at the University of Reading

Reading's research outputs online 


\title{
Gender and the business cycle: an analysis of labour markets in the US and UK
}

\author{
Giovanni Razzu ${ }^{\mathrm{a}, *}$, Carl Singleton ${ }^{\mathrm{b}}$ \\ ${ }^{a}$ Department of Economics, University of Reading, Whiteknights Campus, Reading, RG6 6AA, United Kingdom \\ ${ }^{b}$ Department of Economics, University of Edinburgh, 31 Buccleuch Place, Edinburgh, EH8 9JT, United Kingdom
}

\begin{abstract}
Starting from an improved understanding of the relationship between gender labour market stocks and the business cycle, we analyse the contributing role of flows in the US and UK. Focusing on the post 2008 recession period, the subsequent greater rise in male unemployment can mostly be explained by a less cyclical response of flows between employment and unemployment for women, especially the entry into unemployment. Across gender and country, the inactivity rate is generally not sensitive to the state of the economy. However, a flows based analysis reveals a greater importance of the participation margin over the cycle. Changes in the rates of flow between unemployment and inactivity can each account for around 0.8-1.1 percentage points of the rise in US male and female unemployment rates during the latest downturn. For the UK, although the participation flow to unemployment similarly contributed to the increase of the female unemployment rate, this was not the case for men. The countercyclical flow rate from inactivity to employment was also more significant for women, especially in the US, where it accounted for approximately all of the fall in employment, compared with only $40 \%$ for men.
\end{abstract}

Keywords: Gender, Worker flows, Unemployment, Participation, Great Recession JEL: E24, E32, J16

\section{Introduction}

What is the role of labour market flows in explaining the gender dimension of the business cycle? The sparse analysis carried out to date has typically only described how the stocks of men and women in unemployment respond to aggregate fluctuations. Figure 1 thus illustrates, for both the US and UK, that during economic recessions male unemployment rises faster than female, reducing the gender gap, and in the subsequent recovery, male unemployment falls faster, returning the gender gap to some trend. The relative resilience of the female unemployment rate during a downturn has been explained by one major factor, at least so far as the US is concerned: men and women tend to be occupied in economic sectors that are differently affected by recessions and booms. Occupations that predominantly hire men are typically more cyclical and, therefore, more severely affected by economic recessions (Wood, 2014). ${ }^{1}$ However, the extent to which different responses to the cycle can also be related to the fluidity of the

\footnotetext{
${ }^{*}$ Corresponding author

Email addresses: g.razzu@reading.ac.uk (Giovanni Razzu), c.a.singleton@sms.ed.ac.uk (Carl Singleton)

${ }^{1}$ For the UK there is some evidence that where men and women work cannot explain all of recent cyclical differences, and after controlling for this, during the Great Recession, female job losses were more sensitive to the downturn (Rubery and Rafferty, 2013; Perivier, 2014). Also, Elsby et al. (2013) tentatively suggest that women's real wages were particularly adversely affected by the latest downturn relative to men. Differences in the response of male and female wages, which may not be sectoral, could also be of some relevance.
} 
labour market has largely been overlooked in the literature. ${ }^{2}$ By studying the flows between employment, unemployment and inactivity, we can determine which of the flows into and out of the three states drive the aggregate dynamics of labour market stocks. A flows analysis can tell us something more specific about the sources of the gender business cycle.

Figure 1: Difference from trend of male and female unemployment rates, 16+

(a) US

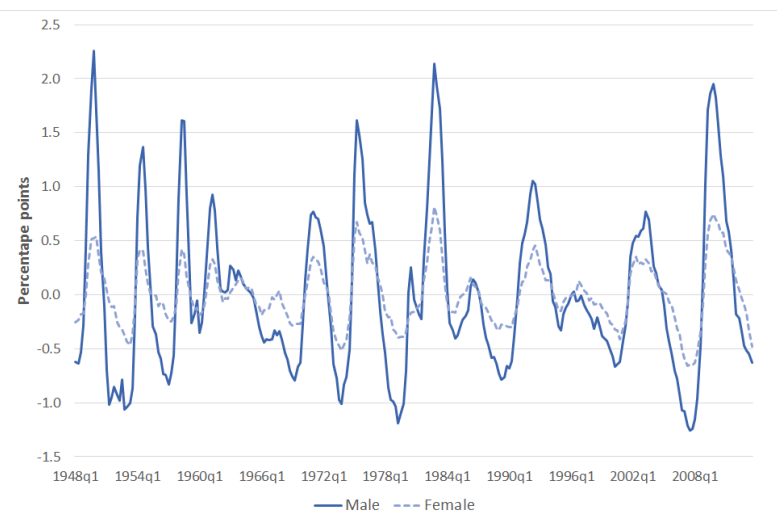

(b) UK

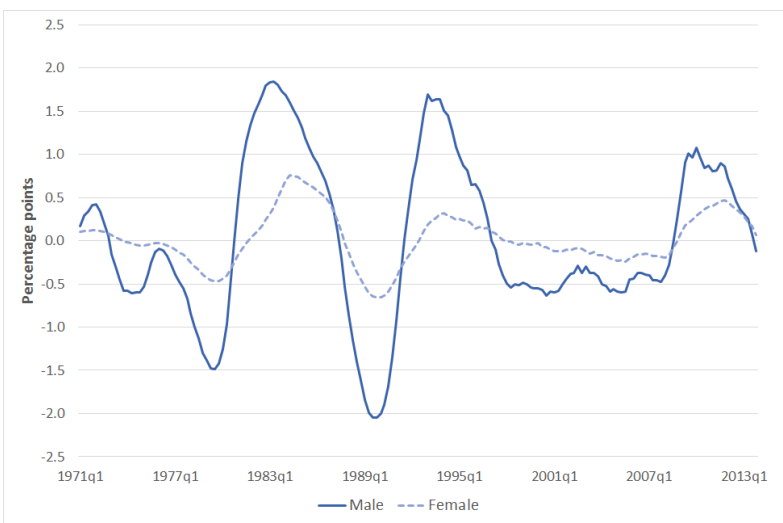

Source.- own calculations from seasonally adjusted CPS (US) \& Labour Force Survey (UK). Detrended using unobserved component model as described in section 2 with constrained frequency parameter to match estimated cyclical periodicity of $\log$ GDP.

Notwithstanding the importance of using stocks to assess the health of the labour market over time, it is now well acknowledged that flows data offer some clear advantages, and the fluidity of the labour market has become the topic of a growing and influential literature since the original contributions of the 1970s. ${ }^{3}$ The empirical analysis of flows has guided the development of the search and matching class of models now most commonly used to understand labour market fluctuations. Analysing flows data can give us more detailed insight into how labour market stocks change, and this could underlie differences in how men's and women's outcomes behave over the business cycle. Has a woman become unemployed because she has lost a job, or because she has completed full-time education and become active in the labour market? Similarly, has a man who has left unemployment done so because he has found a job, or because he has withdrawn from the labour market, perhaps due to disability or other reasons for inactivity? These transitions reveal quite dissimilar experiences, but they become hidden when looking only at the stock of unemployed, employed or inactive persons. In the example of the woman above, the two transitions would both result in an increase in female unemployment, but flows data would tell us that in the first case this was due to a job exit, and in the second case because of a positive labour supply response.

This study not only builds on but goes substantially beyond previous assessments of the relationship between gender and the business cycle, which have been more limited in scope or indirect, whether based on stocks or flows data. ${ }^{4}$ We compare the experiences of the US and UK. These two countries had very similar pre-2008 industry and labour market structures. In

\footnotetext{
${ }^{2}$ For example, see the limited discussion of gender in key literature on labour market flows, such as Elsby et al. (2010, 2011); Shimer (2012). These previous papers moreover do not relate flows back to the overall picture of gender differences in the labour market over the business cycle.

${ }^{3}$ See for example Kaitz (1970); Perry (1972). More recently, important methodological contributions have been provided by Shimer (2005, 2012); Petrongolo and Pissarides (2008); Fujita and Ramey (2009); Solon et al. (2009); Elsby et al. (2010, 2015); Gomes (2012); Smith (2011).

${ }^{4}$ A notable exception to the lack of focus on gender differentials is Albanesi and Sahin (2013), who analysed the trend and cycle properties of the gender unemployment gap. The authors also concluded that, within recessionary
} 
both there is extensive and similar gender segregation of work. ${ }^{5}$ Both countries experienced a significant narrowing of the employment rate gap between men and women since the 1970s, and the speed of this has slowed similarly since the 1990s (figure 2).

Figure 2: Female share of employment, 16+, SA

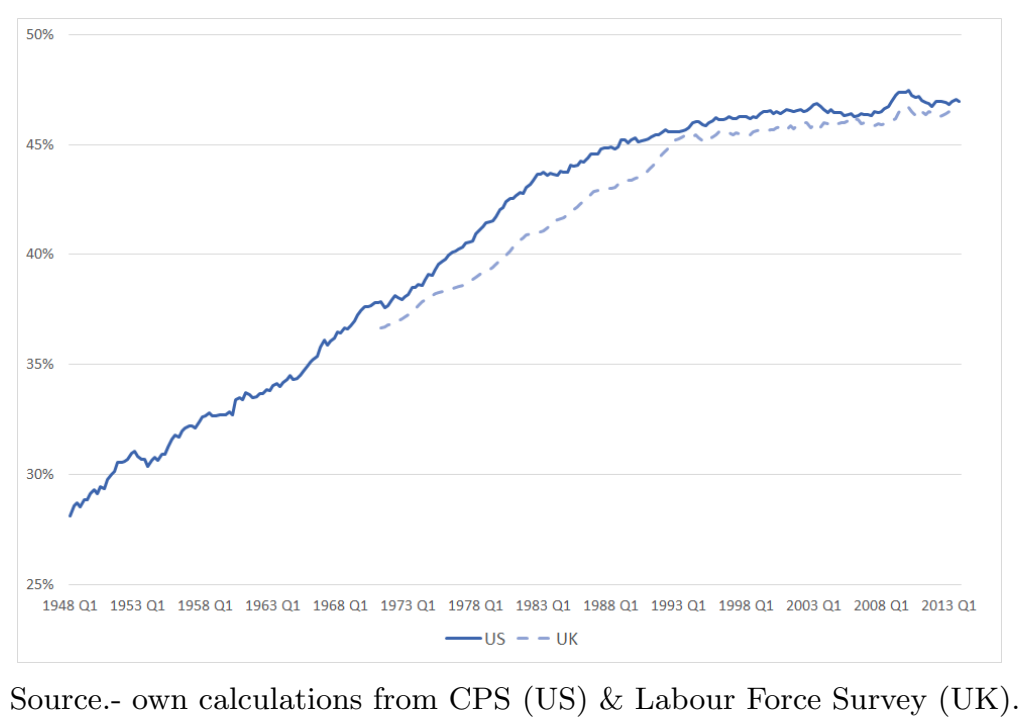

We begin in section 2 by briefly revisiting the reduced form relationship between business cycles and gender labour market rates. Although other studies have estimated the relationship between unemployment rates and the business cycle over time, there is less direct evidence about the response of gender gaps for other statuses. ${ }^{6}$ This broader view is necessary to contrast whether a stocks based view of the labour market reveals less than a flows based approach, specifically with regards gender. The estimated response of the male employment rate is more pronounced than the female, especially during the Great Recession, but this gender gap is not more generally significant. On the other hand, for unemployment rates, business cycles are not gender neutral, and affect men more than women. There are no substantial differences in inactivity rate responses to the cycle.

Given this picture for the stocks in both the US and UK, section 3 moves on to the contributing role of flows. One recent contribution to the flows literature, pertinent to the questions posed here, is the identification of a so-called 'stock-flow fallacy' in the role of the participation margin in shaping the dynamics of the unemployment rate. Accounting correctly for the flows into and out of activity can explain a third of the rise in US unemployment during the 20072012 downturn (Elsby et al., 2015). Theoretical studies of the labour market's response to the business cycle have tended to place less emphasis on the role of the participation margin after noting that inactivity rates remain broadly constant. However, this result is due to the offsetting feature of these flows, and in fact the underlying flows are highly cyclical, and their variation could still explain a large fraction of changes in the unemployment rate. We ask whether or not the stock-flow fallacy for the cyclical importance of the participation margin could extend to gender differences. Is the role of flows between inactivity and activity actually relatively important in explaining labour market outcomes by gender? And is the modest cyclicality of

periods, the male unemployment response in the US is stronger than the female, and this difference has been consistent over time, being mostly explained by the distribution of work by industry.

${ }^{5}$ Compare for example BLS (2013) for the US and ONS (2013) for the UK.

${ }^{6}$ See for examples Clark and Summers (1980); Blank (1989); Peiro et al. (2012); Hoynes et al. (2012) who all note the greater cyclical response of male unemployment than female. 
the inactivity rate, and insignificant or small gender difference, a case of a stock-flow fallacy? To address these, we decompose the variation in labour market stocks during the economic cycle into contributions from the attributing flow hazard rates using a modest modification on the methods of Fujita and Ramey (2009) \& Elsby et al. (2015). Since 1990, as much as a half of the monthly variation in the US gender unemployment rate gap can be accounted for by flows between unemployment and inactivity. This result is robust to adjustments for possible bias in the estimated transition rates. These flows also explain a significant fraction of the evolution of the UK gender gap. Looking specifically at the Great Recession, the majority of the greater rise in male unemployment between 2007 and 2012 in both countries can be explained by a more cyclical response of flows between employment and unemployment than for women, especially for the job separation rate. Movements between inactivity and activity were nonetheless relevant in explaining the variation in recent outcomes. In the US, flows between unemployment and inactivity each contributed around 0.8-1.1 percentage points to the rise in the unemployment rate from 2007 for both men and women. However, for the UK, the flow from inactivity to unemployment does not explain the rise in the male unemployment rate, but can account for around half a percentage point for women. This suggests some macro evidence to support the presence and significance of a so-called 'added worker effect', whereby women are more likely to move from inactivity to activity during periods of economic recession, perhaps to compensate for a partner's loss of job and income. ${ }^{7}$

We also consider the possible presence of this effect at the aggregate level by considering heterogeneity in the flow from inactivity to unemployment, across time and conditional on gender. Generally for all groups, the participation margin in the US was equally affected by the downturn for men and women, and an aggregate added worker effect is unlikely to be gender specific. However, in the UK there are starker differences that suggest a specifically female added worker effect could be a reasonable explanation for the relatively greater importance for women of inactivity to activity flows over the cycle. Although our results focus on unemployment, a notable gender difference also emerges when we consider the contributing role of flows changes to the employment rate. The large and persistent fall in transitions from inactivity to employment observed during the Great Recession explains a large and greater share of the female employment rate fall in both countries.

\section{Reviewing gender business cycles}

\subsection{Data \& Methods}

For both the US and UK we use seasonally adjusted quarterly chained volume measures of real GDP, and (un)employment levels and population ratios for those aged $16+{ }^{8}$ We consider all those aged $16+$ so as to avoid having to make judgements about what constitutes working age over time and across the two countries, however our results are qualitatively unchanged if we restricted attention to ages sixteen to sixty-four. ${ }^{9}$ The series are detrended using both the Hodrick and Prescott (1997) (HP) filter and the unobserved components model (UCM)

\footnotetext{
${ }^{7}$ See Stephens (2002) for an overview of literature concerning the added-worker effect, and for recent analysis of its presence using micro data see Juhn and Potter (2007) and Bryan and Longhi (2013) for the US and UK respectively. See also Mankart and Oikonomou (2015) for a novel theoretical discussion and its role at the aggregate level.

${ }^{8}$ GDP data from BEA, 1947-2013 and ONS, 1955-2013, respectively, and labour market data obtained from BLS, 1948-2013, and ONS, 1971-2013. The estimation window for the US is therefore longer at 1948-2013 compared with 1971-2013 for the UK.

${ }^{9}$ For brevity, the results form this robustness check are excluded here, but are available on request.
} 
methodology of Harvey (1989). ${ }^{10}$

In reviewing the relationship between gender outcomes and business cycles, a helpful starting point is Okun's law, which posits that, in response to some external shock, there is a predictable decomposition into the factors which could comprise some output gap identity. This predictability is dynamic also. Since labour market variables respond slowly, these are lagging indicators of output gaps, and by construction, vice versa for output per employee. We motivate our method here using the most simple identity relating output and labour market outcomes, ${ }^{11}$

$$
Y_{t} \equiv \frac{Y_{t}}{E_{t}} \frac{E_{t}}{N_{t}} N_{t}
$$

where $Y_{t}$ is real GDP, $Y_{t} / E_{t}$ is output per employee, $E_{t} / N_{t}$ is the ratio of employment to population, and $N_{t}$ is the total population. Note also that $U_{t} / N_{t}=1-E_{t} / N_{t}-I_{t} / N_{t}$ is the ratio of unemployed to population, where $I_{t}$ denotes the level of economically inactivity. We take a first order log approximation of (1) around some trend levels, for example $E_{t}^{\tau}$, thus expressing the output gap (or zero sample mean log points from trend of GDP), $y_{t}^{c}$, as a as a tractable additive function of gender (un)employment or inactivity rate trend deviations,

$$
y_{t}^{c}=\frac{E_{t}^{\tau, m}}{E_{t}^{\tau}}\left[e_{t}^{c, m}-n_{t}^{c, m}\right]+\frac{E_{t}^{\tau, f}}{E_{t}^{\tau}}\left[e_{t}^{c, f}-n_{t}^{c, f}\right]+v_{t}
$$

or

$$
y_{t}^{c}=-\frac{U_{t}^{\tau, m}}{E_{t}^{\tau}}\left[u_{t}^{c, m}-n_{t}^{c, m}\right]-\frac{U_{t}^{\tau, f}}{E_{t}^{\tau}}\left[u_{t}^{c, f}-n_{t}^{c, f}\right]-\frac{I_{t}^{\tau, m}}{E_{t}^{\tau}}\left[i_{t}^{c, m}-n_{t}^{c, m}\right]-\frac{I_{t}^{\tau, f}}{E_{t}^{\tau}}\left[i_{t}^{c, f}-n_{t}^{c, f}\right]+\zeta_{t},
$$

where $\{m, f\}$ denote male and female respectively, and $v_{t} \& \zeta_{t}$ capture the behaviour of other variables in the output gap identity such as output per employee, population and an approximation error. Based on (2) \& (3), the cyclical components of male and female (un)employment and inactivity rates, weighted by their trend levels relative to total employment, and consequently the gender employment rate gap, could have a predictable relationship with respect to the business cycle and output gaps. Previous empirical studies of gender, such as Peiro et al. (2012), have tended to ignore both the need to weight or adjust (un)employment rates in this way and the possibility of causality between male and female outcomes, as well as typically only focusing on one labour market variable.

\subsection{Estimation $\&$ results}

We begin by considering the period of the Great Recession only. Using (2) \& (3), figure 3 represents the cumulative contributions of deviations from logarithmic trend of labour market population rates to the output gap, with the final quarter of 2007 indexed to zero. For the US, changes to the labour market accounted for a much greater share of the output gap than the UK. ${ }^{12}$ Changes to male (un)employment accounted for a greater share, with the female contribution in the UK being particularly weak. For both countries and genders there were limited contributions from changes in inactivity rates. Although we could replicate the decomposition of figure 3 for any particular period, and thus describe the gender properties of the business cycle, we also consider a more general approach.

\footnotetext{
${ }^{10}$ See online supplementary appendix A for a brief discussion of detrending methods and summary statistics.

${ }^{11}$ See Gordon (1993) for a discussion of output identities of this type and their implicit role in Okun (1962, 1965).

${ }^{12}$ This is the so-called labour productivity puzzle for the UK observed since the start of the Great Recession, but further discussion here is outside the scope of this study.
} 
Figure 3: Cumulative contribution of changes in labour market variables from trend to the output gap, 2007q4$2012 q 4$

(a) US employment rates

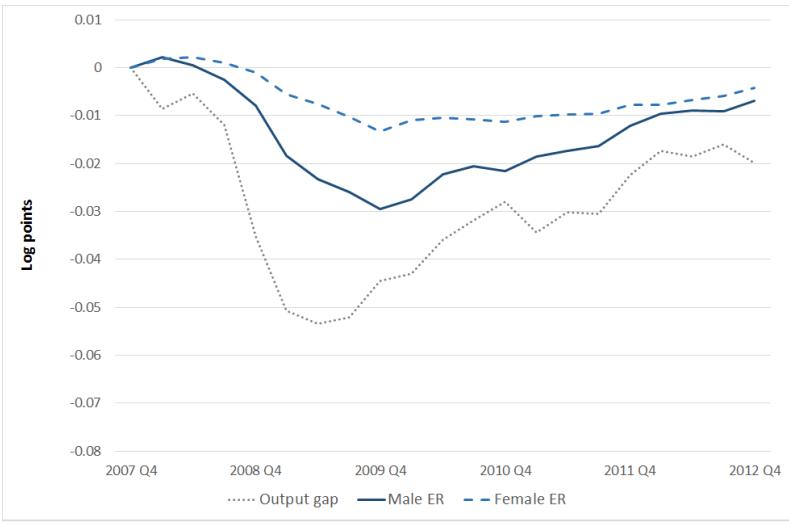

(c) UK employment rates

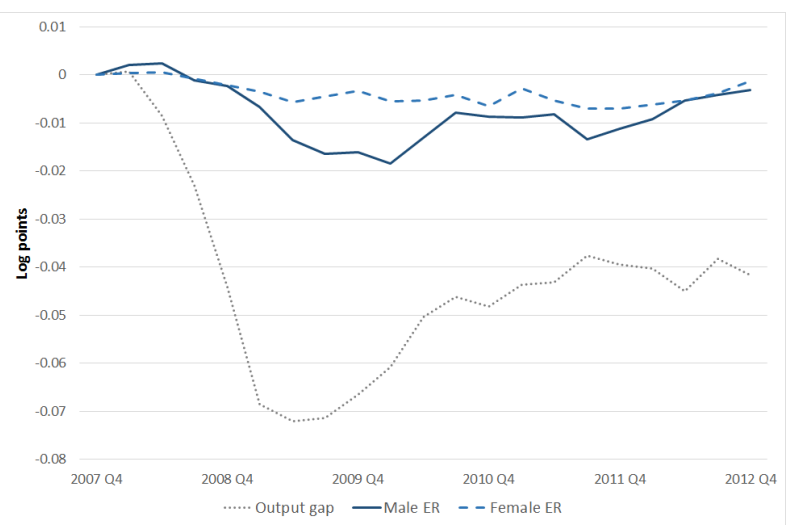

(b) US unemployment and inactivity

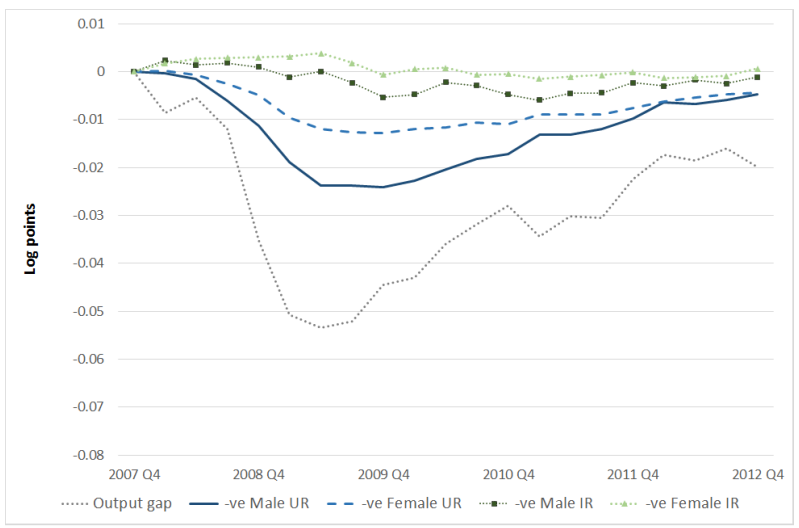

(d) UK unemployment and inactivity

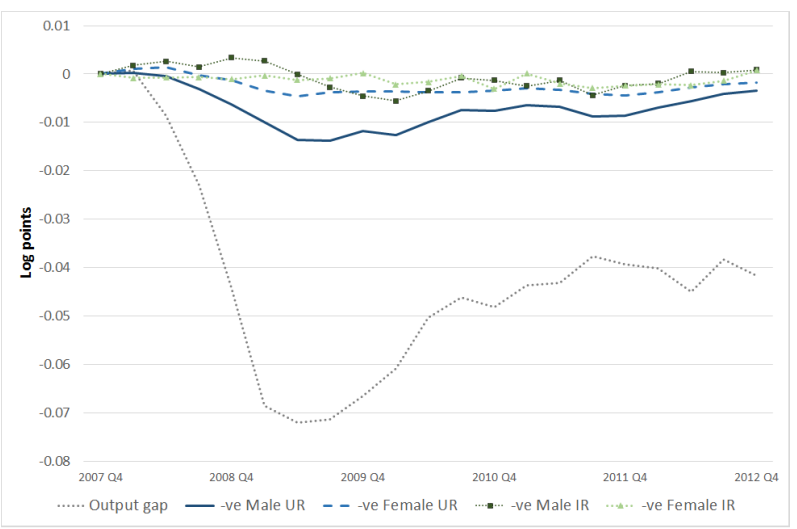

Note.- all series detrended using HP-1600 filter.

To estimate the general properties of the gender business cycle we use a VAR model for the de-trended and subsequently stationary series of the output gap and weighted gender employment rates motivated by (2). ${ }^{13}$ We also estimate the model to study the general responses of inactivity by gender over the business cycle, a surprisingly neglected issue. To do so, based on (3), we replace employment rates in the VAR model with cyclical components of inactivity rates, alongside unemployment population ratios. Finally, to compare our results across the estimated models, we consider impulse responses from an orthogonal shock to GDP which are scaled to give a maximum cumulative output gap increase of approximately one percentage point, and confidence intervals are estimated using non-parametric bootstrapping. ${ }^{14}$

To quantitatively interpret the results of the VAR estimations by gender we 'unweight' the impulse response functions, dividing by the trend weighting factors, e.g. $E_{t}^{\tau, f} / E_{t}^{\tau}$. We can approximately assume that population is constant in the short term such that responses give changes in levels as well as rates. Table 1 shows the maximum cumulative log point changes in the difference from trend of (un)employment and inactivity population rates, following a shock to the output gap which has a maximum cumulative increase of one percentage point, for two time periods; 1975q1 \& 2007q1. For the following discussion we focus on results obtained

\footnotetext{
${ }^{13}$ Alternatively, see Attfield and Silverstone (1998) for an alternative approach to our own whereby the Okun coefficient could be interpreted and estimated as the cointegrating relationship between variables.

${ }^{14} 200$ repetitions. See online supplementary appendix A for a more complete description of the estimation strategy and cumulative impulse response functions for the estimated models, with a brief discussion thereof.
} 
using UCM detrended data and evaluated at 2007 trend levels of gender population rates. The estimated labour market response is typically stronger in the US than the UK, with employment rising 0.6-0.7 \& 0.3-0.5 percent above trend respectively. However, there is no suggestion of a significant gender business cycle for employment. However, the maximum decline in UK male unemployment is more than double the female. The gender response is substantially different also for the US, with male unemployment falling as much as ten percent following such a shock, and only five percent for women. We also see that the implied change in participation over the business cycle is relatively small, as are any gender differences.

Given that this analysis produces results for all three labour market states, direct comparisons with other studies are possible only for the unemployment rate. Peiro et al. (2012) analysed the same countries and roughly similar time periods. They estimate that a four successive quarterly one percentage point increase in the output gap would decrease the US male and female unemployment rates (not de-trended) cumulatively by 2.4 and 1.7 percentage points respectively; and 2.7 and 1.0 points for the UK. Although the comparison is not direct, since the estimated impacts here from such a shock are interpreted as log point deviations from trend, the magnitude of the impacts are roughly similar, and not out of step with the updated Okun hypothesis of a 2:1 percentage point ratio for GDP and unemployment rate changes. ${ }^{15}$ Perhaps more interestingly, Peiro et al. (2012) also suggested that the estimated responses for the UK appear to decrease over time, but not for the US, estimating their model over two sub-samples for each country. ${ }^{16}$ However, this is also consistent with the significant decline over time in UK average unemployment rates, and less so for the US, between these two time periods, which suggests that this result may not be due to a structural change in the effect of the business cycle, but due to the model design. ${ }^{17}$ In fact, when applying the output gap identity model structure, since the average ratio of unemployed to employed has fallen more significantly in the UK than the US for these two periods, and had the cyclical components of unemployment rates not been 'weighted', we might have concluded that the relationship had become stronger over time, when from our own sensitivity analysis over the sample period there is no such evidence.

In summary, focusing on the Great Recession only, there is some evidence of a gender business cycle in both countries. But notably there is little difference in participation response. When considering if this pattern is more general over past decades, there is more limited evidence of a gender business cycle. Women and men in employment are equally affected. Participation changes little and gender differences are small. Unemployment rates respond more for men. Nonetheless, we should not necessarily conclude from these results that the participation margin is not cyclically important, nor that there are no gender differences. To test this further, we also consider the relative importance of flows in and out of participation since these could potentially drive the observed gender difference in unemployment responses to the cycle.

\section{Gender labour market flows}

\subsection{Data}

We use monthly gross flows from the CPS for the US, and derived from the Labour Force Survey (ONS) Two Quarter Longitudinal datasets for the UK. Both surveys have a rotating

\footnotetext{
${ }^{15}$ See for example Lee (2000) for detailed estimates of Okun's law for the UK and US. Baseline estimates are a ratio of 1.84 and 1.39 for the US and UK respectively, and 2.0 as an average across a sample of sixteen OECD countries.

${ }^{16} 1948-1987$ \& 1988-2008 for the US, and 1971-1995 \& 1996-2008 for the UK; these particular results also suggest that over time in the US, the gender difference reverses.

${ }^{17}$ Likewise, the average US female unemployment rate increases in the latter sample period of Peiro et al. (2012), and is higher than the male.
} 
Table 1: Estimated max. cumulative response of population rates from trend to a one percentage point cumulative increase in the output gap

\begin{tabular}{|c|c|c|c|c|}
\hline & \multicolumn{2}{|c|}{ U.S. } & \multicolumn{2}{|c|}{ U.K. } \\
\hline & HP-1600 & $\mathrm{UCM}$ & HP-1600 & $\mathrm{UCM}$ \\
\hline 1975 & & & & \\
\hline Male employment & $\begin{array}{l}0.7^{*} \\
(0.5,0.8)^{* *}\end{array}$ & $\begin{array}{c}0.6 \\
(0.5,0.8)\end{array}$ & $\begin{array}{c}0.6 \\
(0.4,0.9)\end{array}$ & $\begin{array}{c}0.3 \\
(0.1,0.5)\end{array}$ \\
\hline Female employment & $\begin{array}{c}0.6 \\
(0.4,0.8)\end{array}$ & $\begin{array}{c}0.7 \\
(0.5,0.9)\end{array}$ & $\begin{array}{c}0.6 \\
(0.3,0.8)\end{array}$ & $\begin{array}{c}0.5 \\
(0.2,0.8)\end{array}$ \\
\hline $\begin{array}{c}2007 \\
\text { Male employment }\end{array}$ & $\begin{array}{c}0.8 \\
(0.6,1.0)\end{array}$ & $\begin{array}{c}0.7 \\
(0.6,0.9)\end{array}$ & $\begin{array}{c}0.7 \\
(0.4,1.0)\end{array}$ & $\begin{array}{c}0.3 \\
(0.1,0.6)\end{array}$ \\
\hline Female employment & $\begin{array}{c}0.5 \\
(0.4,0.6)\end{array}$ & $\begin{array}{c}0.6 \\
(0.4,0.8)\end{array}$ & $\begin{array}{c}0.5 \\
(0.3,0.7)\end{array}$ & $\begin{array}{c}0.4 \\
(0.1,0.6)\end{array}$ \\
\hline $\begin{array}{c}1975 \\
\text { Male unemployment }\end{array}$ & $\begin{array}{c}-7.6 \\
(-9.2,-6.0)\end{array}$ & $\begin{array}{c}-5.4 \\
(-6.7,-4.2)\end{array}$ & $\begin{array}{c}-10.4 \\
(-14.1,-6.7)\end{array}$ & $\begin{array}{c}-6.9 \\
(-10.3,-3.5)\end{array}$ \\
\hline Female unemployment & $\begin{array}{c}-4.6 \\
(-5.7,-3.5)\end{array}$ & $\begin{array}{c}-4.4 \\
(-5.6,-3.3)\end{array}$ & $\begin{array}{c}-4.4 \\
(-6.3,-2.6)\end{array}$ & $\begin{array}{c}-1.9 \\
(-3.0,-0.7)\end{array}$ \\
\hline Male inactivity & $\begin{array}{c}-0.4 \\
(-0.6,-0.3)\end{array}$ & $\begin{array}{c}-0.4 \\
(-0.5,-0.2)\end{array}$ & $\begin{array}{c}-0.7 \\
(-1.0,-0.5)\end{array}$ & $\begin{array}{c}-0.5 \\
(-0.7,-0.4)\end{array}$ \\
\hline Female inactivity & $\begin{array}{c}-0.1 \\
(-0.2,-0.1)\end{array}$ & $\begin{array}{c}0.0 \\
(-0.1,0.0)\end{array}$ & $\begin{array}{c}-0.2 \\
(-0.3,-0.1)\end{array}$ & $\begin{array}{c}-0.2 \\
(-0.3,-0.1)\end{array}$ \\
\hline $\begin{array}{c}\text { 2007 } \\
\text { Male unemployment }\end{array}$ & $\begin{array}{c}-8.4 \\
(-10.2,-6.6)\end{array}$ & $\begin{array}{c}-10.0 \\
(-12.3,-7.6)\end{array}$ & $\begin{array}{c}-7.2 \\
(-9.7,-4.6)\end{array}$ & $\begin{array}{c}-4.6 \\
(-6.9,-2.4)\end{array}$ \\
\hline Female unemployment & $\begin{array}{c}-5.6 \\
(-6.9,-4.3)\end{array}$ & $\begin{array}{c}-5.1 \\
(-6.5,-3.8)\end{array}$ & $\begin{array}{c}-3.7 \\
(-5.2,-2.2)\end{array}$ & $\begin{array}{c}-1.5 \\
(-2.4,-0.5)\end{array}$ \\
\hline Male inactivity & $\begin{array}{c}-0.4 \\
(-0.5,-0.3)\end{array}$ & $\begin{array}{c}-0.3 \\
(-0.4,-0.2)\end{array}$ & $\begin{array}{c}-0.5 \\
(-0.6,-0.3)\end{array}$ & $\begin{array}{c}-0.3 \\
(-0.4,-0.2)\end{array}$ \\
\hline Female inactivity & $\begin{array}{c}-0.2 \\
(-0.3,-0.1)\end{array}$ & $\begin{array}{c}-0.1 \\
(-0.1,0.0)\end{array}$ & $\begin{array}{c}-0.3 \\
(-0.4,-0.1)\end{array}$ & $\begin{array}{c}-0.3 \\
(-0.4,-0.2)\end{array}$ \\
\hline
\end{tabular}

* interpretation: $100 \mathrm{x} \log$ points from trend change (or approximate percentage points from trend);

** $90 \%$ non-parametric bootstrap confidence intervals.

Note.- using the intervals here, and whether or not they overlap, is not an appropriate check of whether the estimated difference between male and female is statistically significant. Instead, one should use the graphical response functions in the appendix, and also note that the length of time before the max. cumulative response can also differ by gender.

sample. For the UK, the total sample of over one hundred thousand individuals is split into five waves, with one wave leaving the sample and another new wave entering each quarter. Thus it is possible to observe changes in labour market status between quarters of approximately eighty percent of individuals that take part in the survey. The CPS has a similar structure but on a monthly rather than quarterly basis. In any given month the CPS has eight groups, six of 
which will remain in the sample in the next month so that they can be linked longitudinally and individuals' transitions between the three labour market states can be computed. For the UK we use data for men aged 16-64 and women aged 16-59 from 1996 to the second quarter of 2015, smoothing the derived gross flows series with a four quarter moving average. For the US, a research series of seasonally adjusted monthly flows for ages sixteen and over are publicly available from the BLS from February 1990. From these gross flows we compute transition probabilities, namely the probability that an individual moves from one state to another over the period. For example, from the employment to unemployment gross flow, $E U_{t}$, the transition probability is measured as $p_{E U_{t}}=E U_{t} / E_{t-1}$.

Survey based flows estimates are subject to some methodological problems, most notably biases that arise from time aggregation and classification error. ${ }^{18}$ Time aggregation bias arises because of the discrete nature of the data from which we can estimate flow probabilities between states. For instance, a woman might be longitudinally recorded as inactive, followed by employed in the following month or quarter. Whilst we observe only one transition in the data, she could have moved from inactivity to unemployment first, and then from unemployment to employment between responses to the survey. These other transitions are not captured due to the limitation of the data collection frequency. One robust correction to this problem has been provided by Shimer (2012). ${ }^{19}$ We apply the equivalent of this correction to our data, denoting these derived continuous time hazard rates by $f_{i j_{t}}$, but also present results both with and without this correction.

A classification error bias can arise if respondents to the survey are systematically classified as having the wrong labour market status. This problem is known to be particularly relevant in the US data for transitions between unemployment and inactivity. Abowd and Zellner (1985) estimated that more than nine percent of the sample was erroneously classified as inactive instead of unemployed in the original interview. The authors also provided a method to correct for the classification error based on re-interviews of a sub-sample of the CPS. However, reinterview surveys are no longer conducted, meaning that the historical correction might not be applicable to more recent surveys. ${ }^{20}$ Here we apply this correction to the US gross flows as per Poterba and Summers (1986) using the re-interview survey tables in Abowd and Zellner (1985), with separate adjustments for male and female. In terms of gender differences, this correction implies a larger reduction in the relative gross flows $E U, U E, U I \& I U$ for men, with the reduction for $E I \& I E$ greater for women. Importantly for our analysis here, although the correction affects the estimated levels of transitions, and gender gaps, it has little effect on their relative importance in explaining fluctuations in labour market stocks over time. With regards the UK, as noted by Clarke (1999), there is also evidence of significant classification bias, or at least inconsistencies in the longitudinal flows relative to reported state durations, with male inconsistencies for the $I U$ flow being greater. However, there is no equivalent reinterview survey for the UK, and duration data in the survey, which could also be recorded

\footnotetext{
${ }^{18}$ Non-response bias is also potentially an issue, but this has been addressed in the published CPS flows (Frazis et al., 2005), and is accounted for in the longitudinal weights for the UK two quarter datasets (see relevant user guides).

${ }^{19}$ See also the appendix in Elsby et al. (2015) on how the Shimer correction takes the analytical form of an eigendecomposition, which then allows for the numerical computation of all of the underlying continuous time hazard rates.

${ }^{20}$ Elsby et al. (2015) also adopt a novel approach to correct for classification error in the CPS data, which they refer to as "de-NUNification." This is based on the re-coding of unemployment-inactivity flows for each wave over four months so that, for example, if an individual is observed as having the IIUI classification over four periods, this is indiscriminately recoded as $I I I I$. However this is intended mainly as a sensitivity analysis of their main results rather than a robust correction of the estimated time series.
} 
inconsistently, is not sufficient to correct all of the flows. Therefore, this is a limitation of the UK data and an area for further research. ${ }^{21}$

\subsection{Methods}

To estimate the relative importance of changes in each flow rate to gender patterns in the stocks over time we use a version of the three state, non-steady-state decomposition methodology of Elsby et al. (2015). The original literature in this field tended to ignore inactivity rates and participation flows, whereas the three state approach recognises that a fuller picture of labour market dynamics should also take into account flows in and out of inactivity. Other decompositions of unemployment variation are often based on the assumption that the actual unemployment rate is close to its steady-state value, defined as the value of the unemployment rate that would prevail in the long run if the inflow and outflow rates did not change from their current level. ${ }^{22}$ However, this approach could lead to misleading results if the actual unemployment rate deviates persistently from its implied steady-state level, as described for the UK by Smith (2011). To account for this, Smith (2011) proposes a decomposition of changes in the unemployment rate that incorporates the impact of past transition rates, but her method only allows for an analysis of how indirect flows between employment and unemployment via inactivity could explain changes in the stocks. Elsby et al. (2015) note that the discrete time change in the vector of labour market population rates can be re-written as a distributed lag model of past and present changes in implied steady-state levels, and some initial values, thus allowing for a complete decomposition of the change in each population rate into contributions from each flow hazard rate. Our own approach differs from Elsby et al. (2015) in so far as we do not ignore births and deaths to the labour market population in the decomposition, which could be instructive potentially in their contribution to longer term trends in population rates and their gender gaps.

Let the civilian population be normalised to one in each period, i.e. $E_{t}+U_{t}+I_{t}=1$, initially ignoring births (labour market entrants at age sixteen, immigration etc.) and deaths (retirement, emigration etc.), $p_{i j_{t}}$ are discrete transition probabilities, and $k$ denotes each two month/quarter longitudinal period. However, it is possible that $E_{t-1, k}-E_{t-1, k-1}=D_{E, t-1} \neq 0$. When there are more 'births' to employment than 'deaths' $D_{E, t-1}>0$. We refer to this as a 'demography factor.' 23 When analysing changes in the stocks we consider, $\Delta E_{t, k}=E_{t, k}-$ $E_{t-1, k-1}$, i.e. the difference in the second period stock between consecutive two month/quarter longitudinal periods. The relationship between labour market stocks and flows can then be written as

$$
\left[\begin{array}{c}
E \\
U \\
I
\end{array}\right]_{t, k}=\underbrace{\left[\begin{array}{lll}
p_{E E} & p_{U E} & p_{I E} \\
p_{E U} & p_{U U} & p_{I U} \\
p_{E I} & p_{U I} & p_{I I}
\end{array}\right]_{t}}_{M_{t}}\left(\left[\begin{array}{c}
E \\
U \\
I
\end{array}\right]_{t-1, k-1}+\left[\begin{array}{c}
D_{E} \\
D_{U} \\
D_{I}
\end{array}\right]_{t-1}\right) .
$$

Which can be reduced to

$$
\left[\begin{array}{c}
E \\
U
\end{array}\right]_{t, k}=\left[\begin{array}{cc}
1-p_{E U}-p_{E I}-p_{I E} & p_{U E}-p_{I E} \\
p_{E U}-p_{I U} & 1-p_{U E}-p_{U I}-p_{I U}
\end{array}\right]_{t}\left(\left[\begin{array}{c}
E \\
U
\end{array}\right]_{t-1, k-1}+\left[\begin{array}{c}
D_{E} \\
D_{U}
\end{array}\right]_{t-1}\right)+\left[\begin{array}{c}
p_{I E} \\
p_{I U}
\end{array}\right]_{t},
$$

\footnotetext{
${ }^{21}$ See online supplementary appendix B for a brief description and figures of the estimated gender flows time series.

${ }^{22}$ For examples see Petrongolo and Pissarides (2008); Solon et al. (2009); Fujita and Ramey (2009); Gomes (2012); Shimer (2012).

${ }^{23}$ Despite attempts by the statistical agencies to correct for non-response bias in the longitudinal weights applied to the flows, it is still possible that when we disaggregate the data further than intended, i.e. by gender, that these are not perfect, and thus the 'demography factor' may also capture any systematic bias here also. However, we find that this is not a major concern for gender, but when attempting other disaggregations of the labour market, for example types of employment, this can become a greater concern for validity.
} 
or equivalently in simplified notation,

$$
s_{t, k}=P_{t}\left[s_{t-1, k-1}+d_{t-1}\right]+q_{t} .
$$

The steady-state of this system is then given by

$$
\bar{s}_{t, k}=\left(I-P_{t}\right)^{-1}\left[P_{t} d_{t-1}+q_{t}\right] .
$$

Following Elsby et al. (2015),

$$
\Delta s_{t, k}=\left(I-P_{t}\right) \Delta \bar{s}_{t}+\left(I-P_{t}\right) P_{t-1}\left(I-P_{t-1}\right)^{-1} \Delta s_{t-1, k-1} .
$$

And thus, iterating (8) backwards we can write the present change in labour market stocks as a distributed lag function of the change in steady-state values and some initial value for the stocks. Taking a second order approximation of $\bar{s}_{t}$ around lagged values, ${ }^{24}$ and substituting into (8), the change in the stocks in period $t$ is re-written as an additive function of past and present changes of each transition rate $C_{i j_{t}}$, the demography factor $C_{d_{t}}$, and some initial change in the labour market state $C_{0_{t}}$,

$$
\Delta s_{t, k} \approx \sum_{i \neq j} C_{i j_{t}}+C_{d_{t}}+C_{s_{0 t}} .
$$

Given this additively separable representation, we can then decompose the variance of the change in the stocks into contributions from changes in present and past transition probabilities, the initial values, and changes in 'demography.' And so, for example, we can compute, the fraction of the variance of the monthly/quarterly change in unemployment explained by changes in $p_{E U_{t}},{ }^{25}$

$$
\beta_{E U}^{U}=\frac{\operatorname{cov}\left(\Delta U_{t, k},\left\{C_{E U_{t}}\right\}_{2,1}\right)}{\operatorname{var}\left(\Delta U_{t, k}\right)} .
$$

We could also replace the steady-state in (8) with its continuous (or time aggregation bias adjusted) hazard rate, $f_{i j_{t}}$, equivalent, where

$$
\bar{s}_{t}=-F_{t}^{-1} g_{t}-\tilde{d}_{t}
$$

and terms are continuous time equivalents of those in (7). These hazard rates are obtained by solving the ordinary differential equation given by (4), noting that the conditions for the existence and uniqueness of the logarithm of $M_{t}$ are trivially satisfied (see Davies (2010) for an overview), and whereby it can be shown that

$$
\tilde{d}_{t}=-\left(I-P_{t}\right)^{-1} P_{t} d_{t-1} .
$$

The derivatives in the Taylor approximation then take a different analytical form. To derive a decomposition of changes in the active labour force unemployment rate, as opposed to the share of the population unemployed, we use the first order approximation

$$
\Delta u_{t, k} \approx\left(1-u_{t-1, k-1}\right) \frac{\Delta U_{t, k}}{\left(U_{t-1, k-1}+E_{t-1, k-1}\right)}-\left(u_{t-1, k-1}\right) \frac{\Delta E_{t, k}}{\left(U_{t-1, k-1}+E_{t-1, k-1}\right)} .
$$

In what follows we also discuss how changes in flow rates account for variation in the percentage point gender (un)employment rate gap. This is derived by subtracting the female decomposition of the change in the population rates (9) from the male equivalent.

\footnotetext{
${ }^{24}$ As used in other studies, a first order approximation is sufficient for a cyclical analysis since the approximation error does not correlate, but we nonetheless find that including second order terms, excluding the cross-derivatives, reduces the size of the errors significantly.

${ }^{25}$ For a complete description of the variance flows decomposition methodology see also Fujita and Ramey (2009).
} 


\subsection{Results}

\subsubsection{Unemployment rate variation}

Tables 2 summarizes the results for the above decomposition for the US and UK unemployment rates. ${ }^{26}$ Entries for the US show the estimated fraction of monthly variation in unemployment from June 1990 to August 2015 accounted for by variation in each component of the decomposition, i.e. the $\beta$ s as per (10). UK entries similarly show computed results for quarterly variation between the third quarter of 1997 and second quarter of 2015. Each table shows results using flow transition probabilities, $p_{i j}$ and hazard rates which have been adjusted for the presence of time aggregation bias in the flows, $f_{i j}$. Cyclically this bias tends to lead to a substantial underestimation of the relative importance of flows from unemployment, offset by an overestimation for the reverse flows. For example, using unadjusted transition probabilities would for both countries underestimate the $U E$ flow's relative importance in explaining employment and unemployment rate variation by as much as a third. Additionally, for the US we give results including the constant Abowd and Zellner (1985) correction for classification bias. The adjustment implies that the estimated importance of the $U I$ flow for unemployment variation would otherwise be biased downwards, and vice versa for the $I U$ flow. However, although this substantially affects the magnitude of estimated flow rates, it has less impact on the results of the cyclical analysis. ${ }^{27}$ For both countries in what follows we focus on results using hazard rates corrected for time aggregation bias, $f_{i j}$.

When making cross-country comparisons here we must be conscious that we are comparing results using monthly and quarterly derived transitions. By applying the time aggregation bias correction we should theoretically be accounting for this difference. But as noted by Gomes (2015), who applies the correction to US transitions from the CPS at both monthly and quarterly frequencies, the effect on cyclical properties of the estimated flows can differ depending on the frequency of the data. This is because the correction assumes the flow hazard rate is constant over time for all workers. In reality it isn't, varying with tenure and unemployment duration for example. Therefore he suggests comparisons across countries should at least use similar frequency data. However, this critique should not apply to comparisons of gender differences within country: we can assume that the effects of applying the bias correction to flows measured over the same periodicity will be similar for men and women.

For the unemployment rate in the US, over half of the variation in changes for both men and women can be attributed to the combined exits to employment and inactivity. However, the composition of this variance share differs, with the exit to inactivity, $U I$, being relatively more important in explaining the path of female unemployment. However, this small measured difference in the importance of the $U I$ flow, twenty-five vs nineteen percent, could disguise a larger actual difference in responses to the cycle. If we accept that the labour market attachment of unemployed women is generally lower, and if the procyclical $U I$ hazard rate is largely explained by composition effects on the pool of those unemployed, as hypothesised by Darby et al. (1986) and demonstrated in Elsby et al. (2015), then, we would have expected the importance of the male flow to be greater through this composition channel alone. Differences in the relative importance of flows into unemployment are also greater. The $E U$ flow is almost twice as important for male employment changes than it is for female, and vice versa for the $I U$ flow.

\footnotetext{
${ }^{26}$ For brevity here, and as consistent with the focus of the literature, results and a discussion of the decomposition for the employment rate is included only in the supplementary appendix. However, when we focus on the Great Recession period later we do draw out some pertinent gender differences which can only be seen from the employment rate results.

${ }^{27}$ These biases in the estimates can also be discerned by scrutinising the flow rates time series given by figures $\mathrm{B} 2-\mathrm{B} 7$ in the online appendix B.
} 
For men and women combined flows between unemployment and inactivity explain thirty-four and forty-nine percent of the variance in unemployment rate changes, emphasising again the importance of the labour market participation margin for both genders over the cycle.

Table 2: Flows decomposition of monthly changes in the unemployment rate and gender gap

\begin{tabular}{|c|c|c|c|c|c|c|c|c|c|c|}
\hline & & $U E$ & $E U$ & $E I$ & $U I$ & $I E$ & $I U$ & Init. val. & $d$ & approx. err. \\
\hline \multicolumn{11}{|c|}{ US: June 1990 - August 2015} \\
\hline \multirow{4}{*}{$p_{i, j}$} & All & $0.29^{*}$ & 0.27 & -0.02 & 0.16 & 0.04 & 0.24 & 0.00 & 0.00 & 0.01 \\
\hline & Male & 0.28 & 0.33 & -0.01 & 0.14 & 0.03 & 0.21 & 0.00 & 0.00 & 0.01 \\
\hline & Female & 0.25 & 0.22 & -0.03 & 0.18 & 0.04 & 0.33 & 0.00 & 0.01 & 0.01 \\
\hline & $\operatorname{Gap}^{* *}$ & 0.12 & 0.38 & 0.01 & 0.18 & 0.00 & 0.30 & 0.00 & 0.00 & 0.00 \\
\hline \multirow[t]{4}{*}{$f_{i, j}$} & All & 0.39 & 0.20 & -0.02 & 0.22 & 0.03 & 0.17 & 0.00 & 0.00 & 0.01 \\
\hline & Male & 0.37 & 0.26 & -0.01 & 0.19 & 0.02 & 0.15 & 0.00 & 0.00 & 0.01 \\
\hline & Female & 0.34 & 0.15 & -0.03 & 0.25 & 0.04 & 0.24 & 0.00 & 0.01 & 0.01 \\
\hline & Gap & 0.17 & 0.33 & 0.01 & 0.22 & 0.00 & 0.27 & 0.00 & 0.00 & 0.00 \\
\hline \multirow{4}{*}{$f_{i, j}$ w. AZ corr. } & All & 0.42 & 0.22 & -0.03 & 0.25 & 0.03 & 0.09 & 0.00 & 0.00 & 0.01 \\
\hline & Male & 0.39 & 0.29 & -0.01 & 0.21 & 0.02 & 0.09 & 0.00 & 0.00 & 0.01 \\
\hline & Female & 0.36 & 0.16 & -0.03 & 0.27 & 0.04 & 0.18 & 0.00 & 0.01 & 0.01 \\
\hline & Gap & 0.17 & 0.36 & 0.00 & 0.21 & 0.00 & 0.25 & 0.00 & 0.00 & 0.00 \\
\hline \multicolumn{11}{|c|}{ UK: q3 1997 - q2 2015} \\
\hline \multirow[t]{4}{*}{$p_{i, j}$} & All & 0.28 & 0.32 & -0.01 & 0.14 & 0.03 & 0.14 & 0.07 & 0.02 & 0.01 \\
\hline & Male & 0.26 & 0.36 & -0.01 & 0.12 & 0.01 & 0.10 & 0.10 & 0.04 & 0.02 \\
\hline & Female & 0.28 & 0.23 & 0.00 & 0.16 & 0.04 & 0.21 & 0.02 & 0.04 & 0.00 \\
\hline & Gap & 0.15 & 0.35 & 0.00 & 0.13 & -0.02 & 0.07 & 0.13 & 0.18 & 0.01 \\
\hline \multirow[t]{4}{*}{$f_{i, j}$} & All & 0.36 & 0.25 & -0.01 & 0.19 & 0.03 & 0.08 & 0.07 & 0.02 & 0.01 \\
\hline & Male & 0.32 & 0.31 & -0.01 & 0.15 & 0.02 & 0.06 & 0.10 & 0.04 & 0.02 \\
\hline & Female & 0.38 & 0.16 & -0.01 & 0.24 & 0.05 & 0.11 & 0.02 & 0.05 & 0.00 \\
\hline & Gap & 0.19 & 0.30 & 0.00 & 0.15 & -0.03 & 0.06 & 0.13 & 0.18 & 0.01 \\
\hline
\end{tabular}

$* \beta_{U E}^{u}$ is approximated from equivalent components for the unemployment and employment population shares as per (13) for current and past changes in the $U E$ transition probability.

** Gender gap computed as male unemployment rate minus female.

Note: rows may not sum to one due to rounding errors.

Specifically focusing on the evolution of the US gender unemployment rate gap over the past 25 years, around a third of its variation can be explained by greater volatility in male entries from employment, a half by the combined difference in transitions rate changes between unemployment and inactivity, and the remaining sixth by the difference in volatility of exits to employment. Crucially for robustness of this result, these shares are not substantially altered when we either remove the time aggregation bias correction or add the adjustment for classification error in the gross flows.

The results for the UK are qualitatively similar to the US. Exits explain a greater share of female unemployment variation than male, sixty-two vs forty-seven percent, with the majority of this difference accounted for by the $U I$ rate. The contribution of the reverse $I U$ flow to variation over the last two decades is relatively small, although greater for women. Departures from employment to the unemployment pool explain half as much of the variation in the female unemployment rate as the male. With regards explaining changes in the gender gap, the variance of the entry rates to unemployment is more important than any gender difference in exits. The 
combined changes in flows between unemployment and inactivity can account for approximately a fifth of the gap's variation. Compared loosely with the US, inactivity flows therefore appear less significant. This is most likely explained by institutional differences and social welfare eligibility conditions, which in the UK encourage individuals to remain active in the labour market continuously. A major conclusion from these stock-flow decompositions is again to reiterate the cyclical importance of the participation margin, and add to the evidence in Elsby et al. (2015) by showing this is not unique to the US.

\subsubsection{The Great Recession}

Given our short sample period containing only the one major downturn, our results above ought to be driven by the labour market experiences of men and women during the Great Recession. Therefore, using the stocks decomposition as an accounting identity, we can focus more precisely on how the evolution of unemployment rates between 2007 and 2012 was determined by changes in the underlying hazard rates. Figures $4 \& 5$ give the cumulative contributions of changes in each of the hazard rates to the percentage point change in the unemployment rate by gender, indexed to zero at the end of 2007 . Here the gender differences in the relative importance of the flow rates become clearer, and their contributions to the change in the unemployment rate gap during this time can be read off indirectly. For the US, unemployment exits to employment for both men and women explain around a third of the initial rise in unemployment to the end of 2008 , with this rising to a half by the time the unemployment rate hits its peak towards the end of 2009. The fall in the unemployment exit rate contribution persists then through to 2010, despite the fall in the unemployment rate seen especially for men. This differing pattern of unemployment over the cycle appears to be driven by the greater contribution of the $E U$ rate, which for men peaks with unemployment, and then declines to pre-recession levels. However, the rise in this entry rate to unemployment never substantially contributes to the stock of unemployed women. The procyclical decline in the $U I$ flow, and the countercyclical rise in the $I U$ flow, contribute each to the unemployment rate increase for men and women by around 0.8-1.1 percentage points at its peak level. Thus, despite explaining a greater share of the female unemployment rise within the recession, the rise in the gender gap cannot be significantly explained by the participation margin, whereas over the past 25 years more generally, changes in these flows can explain a much larger share of the gap's variation.

Similarly for the UK, the persistent decline in the $U E$ flow can explain a large part of the rise in male and female unemployment rates, and the difference in their evolution since 2007 can largely be accounted for by the relatively muted rise in $E U$ transitions for women. However, unlike for the US, the rise in the participation flow to unemployment for men, $I U$, explains none of the unemployment rate change, whereas for women it can account for around half a percentage point.

The more significant rise in male unemployment from 2007 in both countries can mostly be accounted for by differences in the magnitude of responses to the downturn of the flows between employment and unemployment. However, the relative insensitivity of the inactivity rate to the business cycle belies the important role that changes in the rates individuals move into and out of the active labour force have in determining the rise in unemployment. Further, for the UK there is some evidence that an aggregate gender specific 'added worker' effect could be present, manifested by a countercyclical $I U$ hazard rate for women and absence of the like for men.

The employment change over the period can likewise be decomposed into its specific flow rate contributions. An interesting feature of the Great Recession has been the relative role of the procyclical $I E$ flow. The collapse in this transition rate, and especially the persistence of this fall, is largely a puzzle (Kroft et al., 2014). Figure 6 demonstrates how this can account 
Figure 4: US cumulative percentage point contributions from changes in hazard rates to the unemployment rate change, 2008-2012

(a) Male - EU \& UE

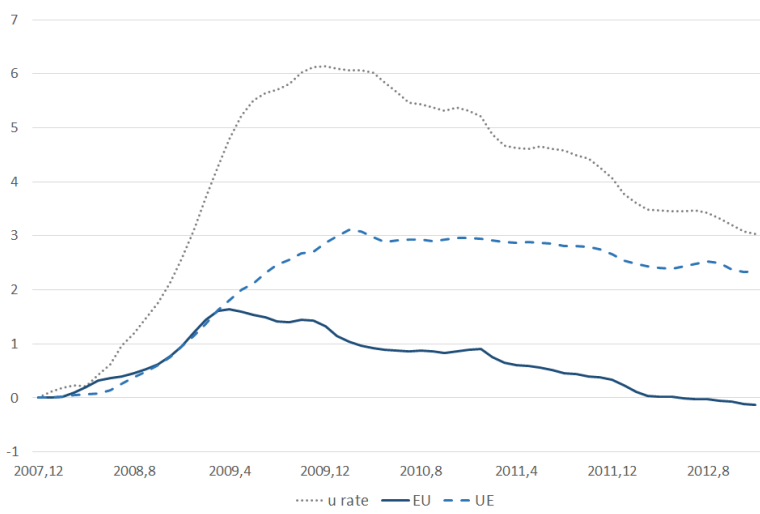

(c) Male- EI \& IE

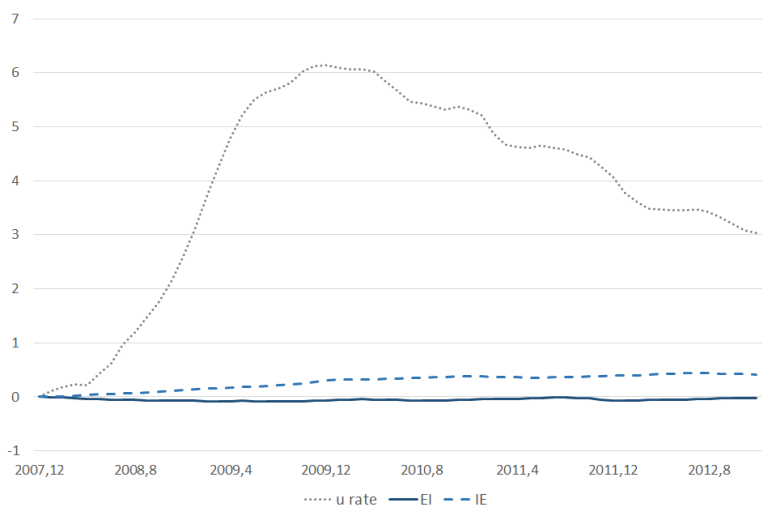

(e) Male - UI \& IU

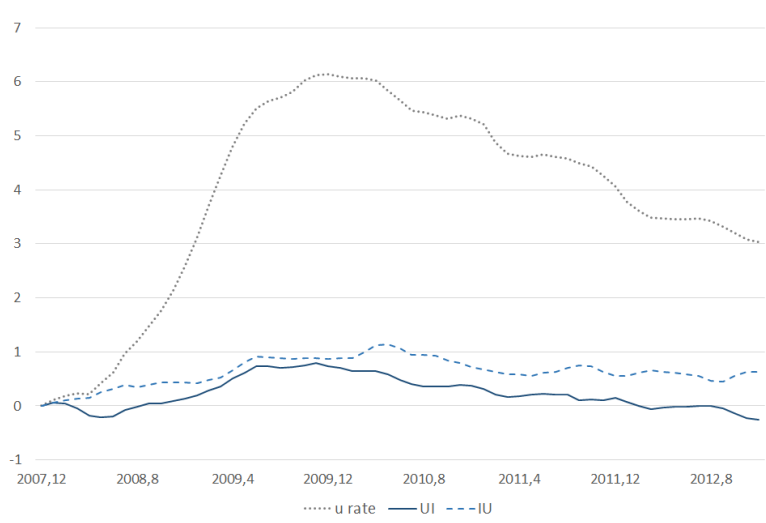

(b) Female - EU \& UE

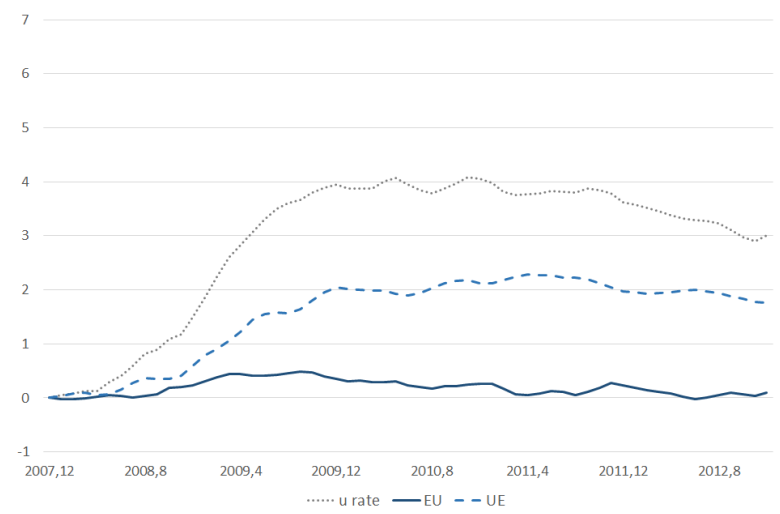

(d) Female - EI \& IE

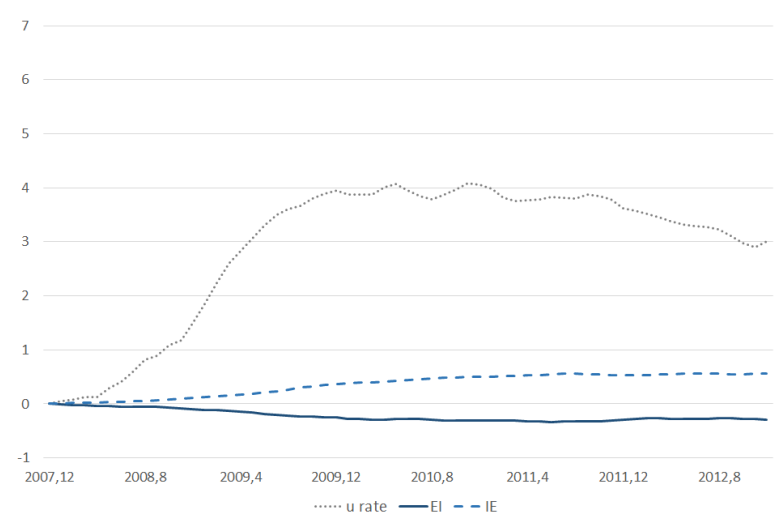

(f) Female - UI \& IU

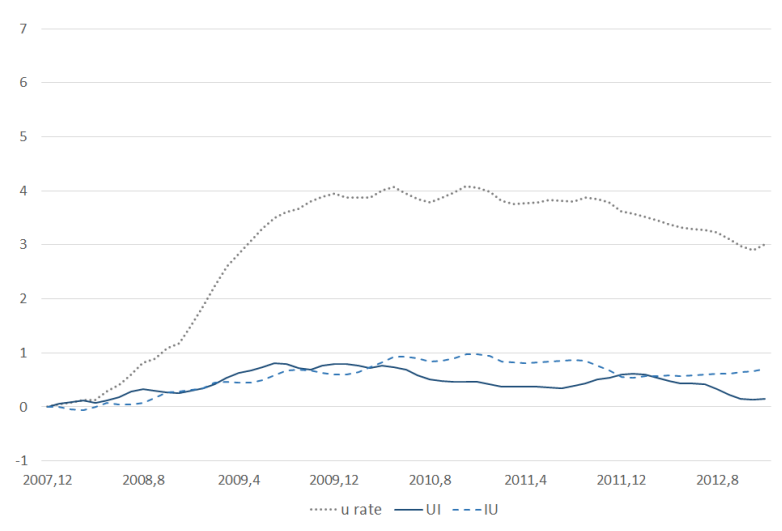

Note.- hazard rates here are calculated without the Abowd and Zellner (1985) correction for classification error to the gross flows.

for a large part of the fall in employment to 2012, even as compared with the decline in entries from unemployment, the most cyclically important flow rate. There is also some common gender difference in the significance of this flow across countries. In terms of absolute percentage points, $I E$ transitions account for a similar amount of the employment rate fall for both sexes in the UK, and over half a point more for women in the US. However, given the smaller decrease in female employment, it remains a demonstrably more relevant cyclical factor for women. For example, in the US, by the end of 2010 it accounts for approximately all of the female employment fall, notwithstanding the offsetting contributions of other flows, as opposed to only $40 \%$ for men. 
Figure 5: UK cumulative percentage point contributions from changes in hazard rates to the unemployment rate change, 2008-2012

(a) Male - EU \& UE

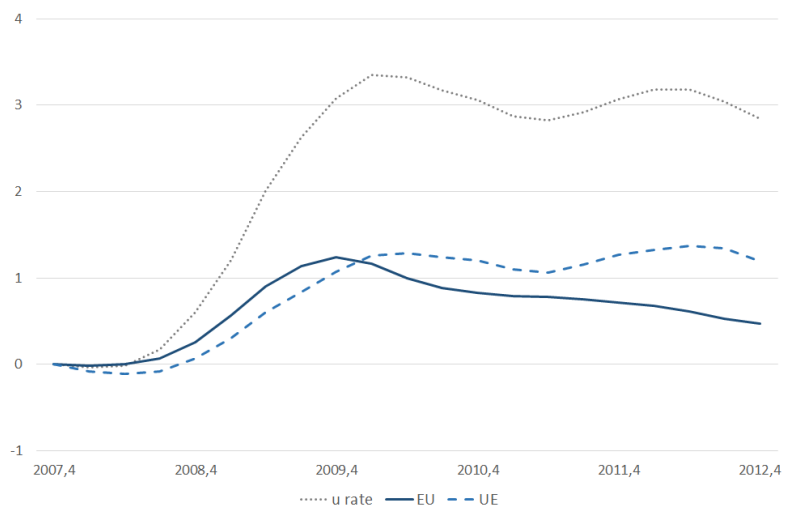

(c) Male - EI \& IE

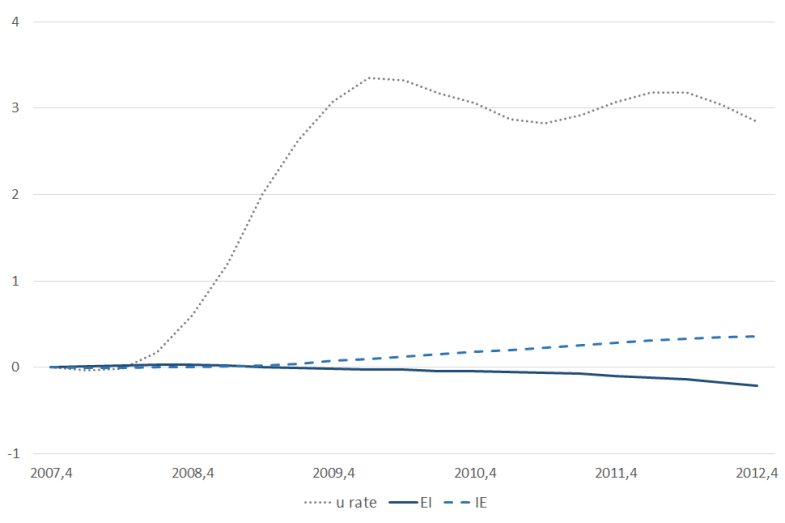

(e) Male - UI \& IU

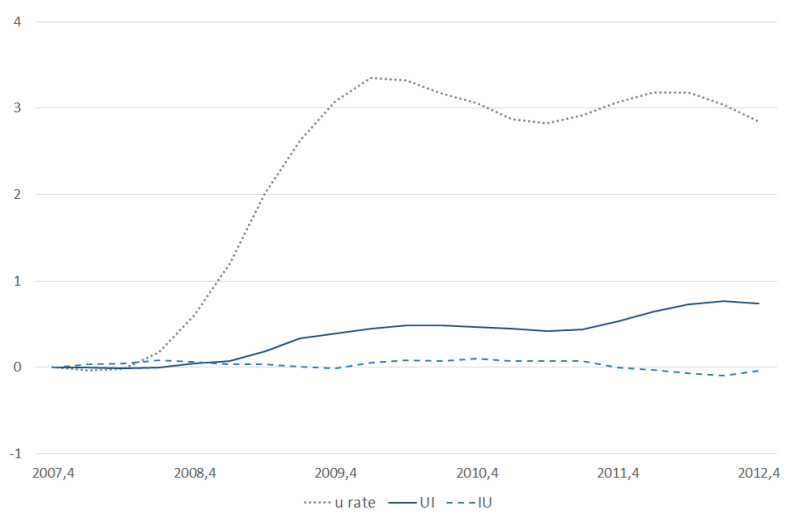

(b) Female - EU \& UE

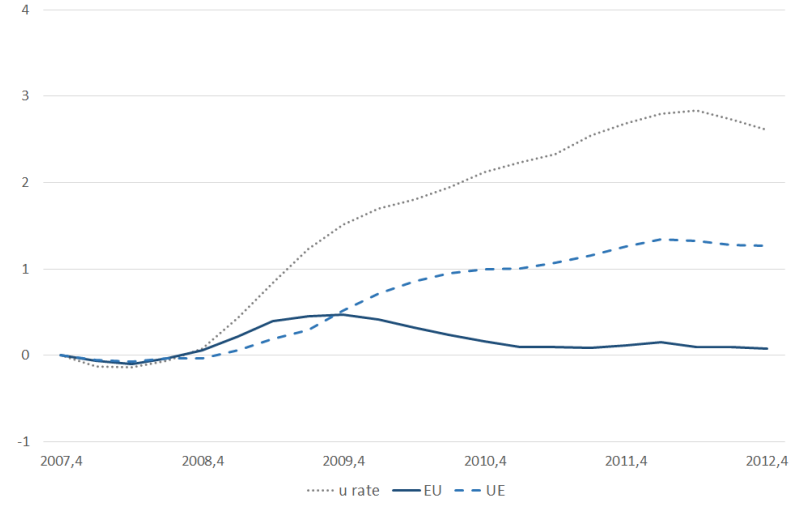

(d) Female - EI \& IE

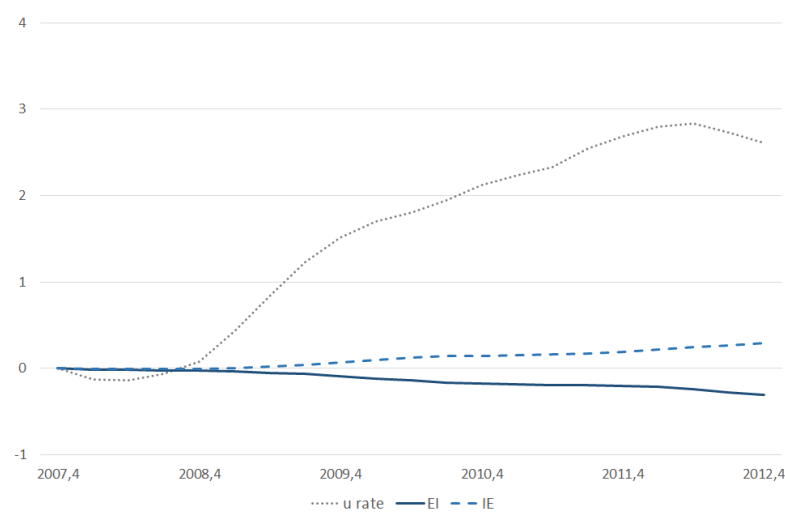

(f) Female - UI \& IU

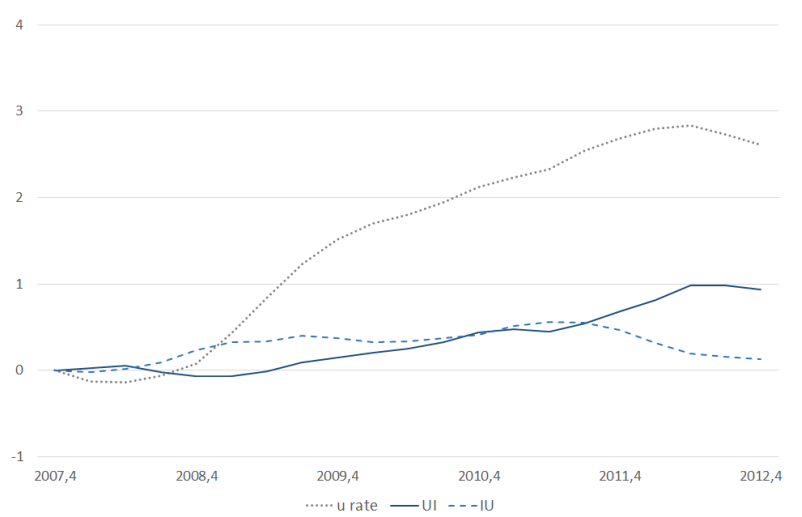

\subsubsection{Heterogeneity in the IU flow rate}

We can explore the possible presence of the added worker effect by considering heterogeneity in the $I U$ transition rate, across time and conditional on gender. Focusing on individuals aged 20-54, we consider age, the age of the youngest child in the family, the number of dependent children, whether living as a married couple, when an individual left their last job, reasons for leaving, and their more detailed inactivity status. ${ }^{28}$ We compute the US monthly and UK quarterly transition probabilities for men and women defined by these various characteristics and we average these probabilities over two broad time periods: one ending before the start of

\footnotetext{
${ }^{28}$ For the US, survey responses of when an individual left their last job, and reasons for leaving are either not available or reliable for those who are inactive.
} 
Figure 6: Cumulative percentage point contributions from changes in entry hazard rates to the employment rate change, 2008-2012

(a) US Male

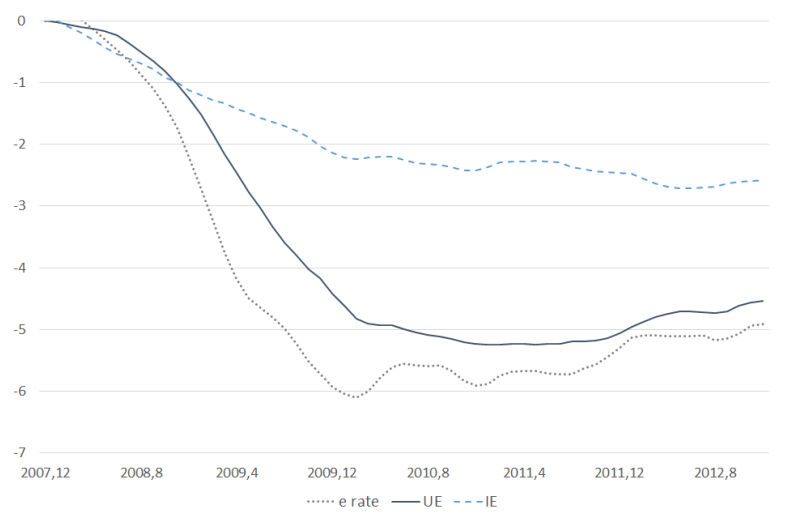

(c) UK Male

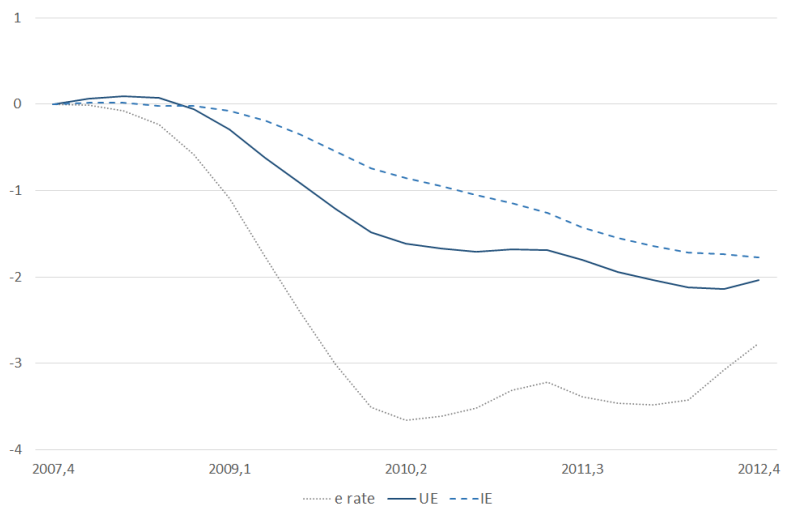

(b) US Female

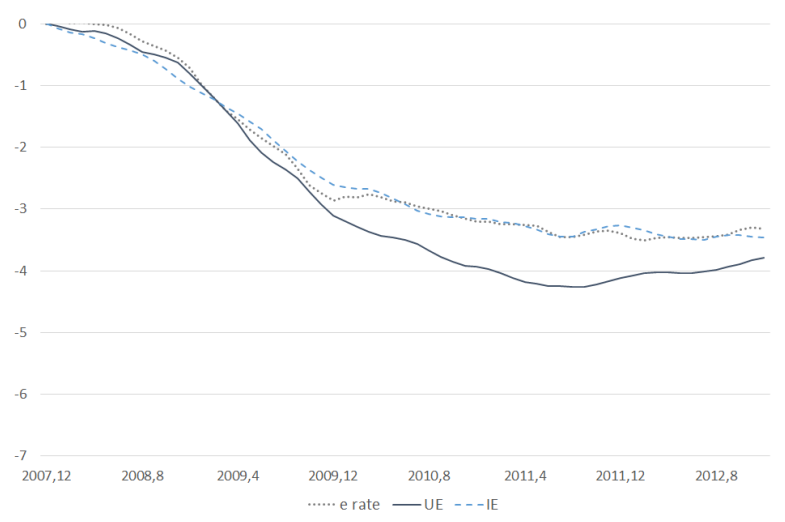

(d) UK Female

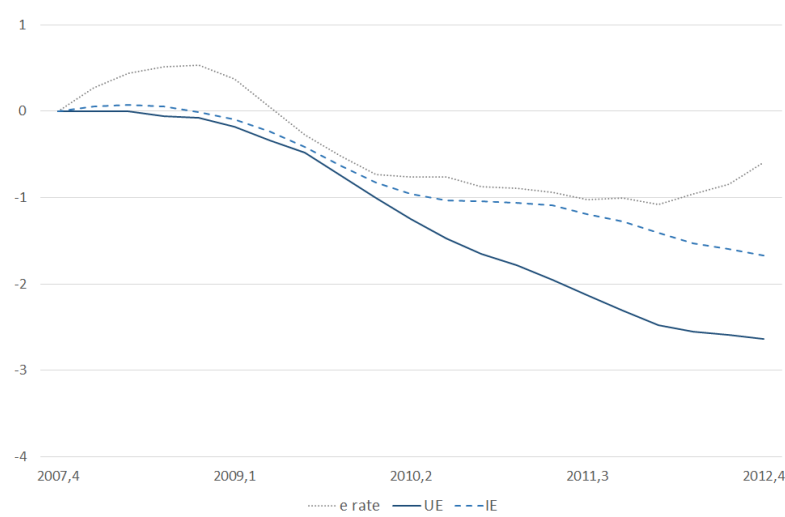

Note.- US hazard rates here are calculated without the Abowd and Zellner (1985) correction for classification error to the gross flows.

the latest economic downturn, 1997 to 2007, and the second capturing broadly the period of the Great Recession, 2008 to 2012 (see tables D1 \& D2 in the online appendix D). It is not possible to carry out a time aggregation or classification error bias adjustment on these transitions. But especially for time aggregation, we should not expect these biases to be systematic with gender and time. If we only consider the pre-recession period, for both countries, across all groups, the male flow probability from inactivity to unemployment is greater than the female. This implies that men, when inactive, are closer to the labour market than women, even controlling for type of inactivity. Looking within types of heterogeneity, the relative difference between the flow probability for men who declare themselves to be inactive because they are looking after the family or home, and other inactivity groups, is higher than for women. Furthermore, in both countries again, the male flow probability decreases with the age of youngest child, as opposed to increasing for women (although only marginally so for the US).

Have these patterns changed since the Great Recession? To answer this we consider changes between the two broad time periods (table 3). For the US, there were large increases in the monthly flow probability for both men and women who are inactive looking after the family or home, as well as for those with young children. Likewise, the probability of transition for married men increased by over fifty percent, and a third for women. These are groups of individuals for whom we might expect to see large countercyclical increases in transition probabilities if a theoretical added worker effect were relevant. Based simply on these unconditional averages over time, it would appear as though this is equally the case for men and women. Those without 
dependent children, or not living as a married couple, both male and female, appear to be less affected than those with. Generally, across all groups it appears as though the participation margin in the US is equally affected by the downturn for men and women. However, in the UK, there are more stark differences. Younger men, and those in full-time education, see a smaller rise in their likelihood of rejoining the labour market via unemployment than do women. Across most groups, the male flow is less cyclical. More relevantly to the hypothesised added worker effect, the rise in the flow probability for those looking after family or home is twenty \& thirtynine percent respectively for men and women, and the equivalent figures for those with children aged zero to one are six and forty-one percent. The differences remain large for those with youngest child aged two to four also. Women living as a married couple are a third more likely to move from inactivity to unemployment during the Great Recession whereas the male transition barely increases. Like the US, having no dependent children is associated with a relatively smaller increase in the flow probability. Therefore, while in the US these simple average flow probabilities suggest that an added worker effect might not be gender specific, for the UK we find more associated evidence that it is. This may contribute to the aggregate gender difference in the cyclical importance of the participation margin in explaining changes in unemployment rates observed for the UK, and also why this is not the case over the same period for the US.

Table 3: Percent change in $p_{I U}$ from $1997-2007$ to $2008-2012$

\begin{tabular}{|c|c|c|c|c|c|}
\hline & & U.S. & & U.K. & \\
\hline & & Male & Female & Male & Female \\
\hline \multirow[t]{3}{*}{ Age } & $20-29$ & 20.8 & 28.1 & 11.0 & 33.2 \\
\hline & $30-39$ & 52.7 & 38.1 & 4.9 & 28.8 \\
\hline & $40-54$ & 52.1 & 44.6 & 28.3 & 26.2 \\
\hline \multirow[t]{5}{*}{ Inactivity reason } & Retired & -14.4 & 1.3 & 33.1 & 21.3 \\
\hline & Disabled & 23.6 & 23.9 & 22.3 & 41.5 \\
\hline & Family/home & 36.9 & 43.5 & 20.1 & 39.2 \\
\hline & Student & 28.6 & 25.3 & 9.2 & 25.9 \\
\hline & Other & 33.6 & 43.3 & 11.6 & 19.4 \\
\hline \multirow{3}{*}{$\begin{array}{l}\text { When left last job } \\
\text { ( } \tau \text { months })\end{array}$} & $\tau \leq 12$ & & & 17.0 & 23.8 \\
\hline & $\tau>12 /$ never & & & 24.2 & 38.3 \\
\hline & & & & 0.0 & 0.0 \\
\hline \multirow{3}{*}{ Reason left last job } & Job loser & & & 28.0 & 17.9 \\
\hline & Job leaver & & & 26.7 & 35.2 \\
\hline & Temp. job ended & & & 13.5 & 10.6 \\
\hline \multirow[t]{2}{*}{ Living as a married couple } & Yes & 49.1 & 36.6 & 5.2 & 33.6 \\
\hline & No & 34.7 & 25.8 & 15.3 & 26.5 \\
\hline \multirow[t]{3}{*}{ Age of youngest child } & $0-2 / 0-1$ & 43.8 & 48.5 & 6.6 & 41.4 \\
\hline & $3-5 / 2-4$ & 62.0 & 54.6 & 17.8 & 38.5 \\
\hline & $6-13 / 5-9$ & 74.6 & 28.8 & 18.0 & 28.9 \\
\hline \multirow[t]{5}{*}{ Number of dep. children $<18 / 19$} & 0 & 39.2 & 37.7 & 15.3 & 28.9 \\
\hline & 1 & 55.2 & 51.7 & 38.9 & 38.5 \\
\hline & 2 & 71.9 & 41.5 & 29.2 & 32.9 \\
\hline & 3 & 57.3 & 39.7 & 5.9 & 24.5 \\
\hline & $\geq 4$ & 43.0 & 13.3 & -29.2 & 33.0 \\
\hline
\end{tabular}




\subsection{Further discussion}

Our analysis suggests a greater cyclical importance of $I U$ flows for men in the US than in the UK during the Great Recession. Before making too much out of this cross-country result, we must be confident that these observed differences do not emerge from the types of data we have used, in particular the frequency over which we have estimated hazard rates. It is possible that the counter-cyclical US male $I U$ transition and observed cyclical neutrality for the UK could be accounted for by frequent back and forth transitions between unemployment and inactivity for men within the quarter, even after our corrections for other biases in the flow rates. For example, the recorded quarterly $U U$ flow in the UK would be equivalent to the $U N N U$ chain over four months seen in the US data. To check whether this drives our results, we use waves one and five matched with four \& eight from the CPS to estimate a quarterly series of gross US flows by gender for each month. In figure 7 we see that the strong counter-cyclicality of the male quarterly transition probability remains, and this appears at least as significant for women over the downturn. The differing cross-country male participation response to the Great Recession could be a result of inactive men in the UK having a particular set of characteristics that put them further from the labour market, relative to women, than is the case for those in the US. Future research could assess whether inactive men in the UK and the US, otherwise identical along relevant observable characteristics such as marital status and number of dependent children, have residually different probabilities of moving from inactivity to unemployment.

Figure 7: Estimated quarterly US transition probability from inactivity to unemployment

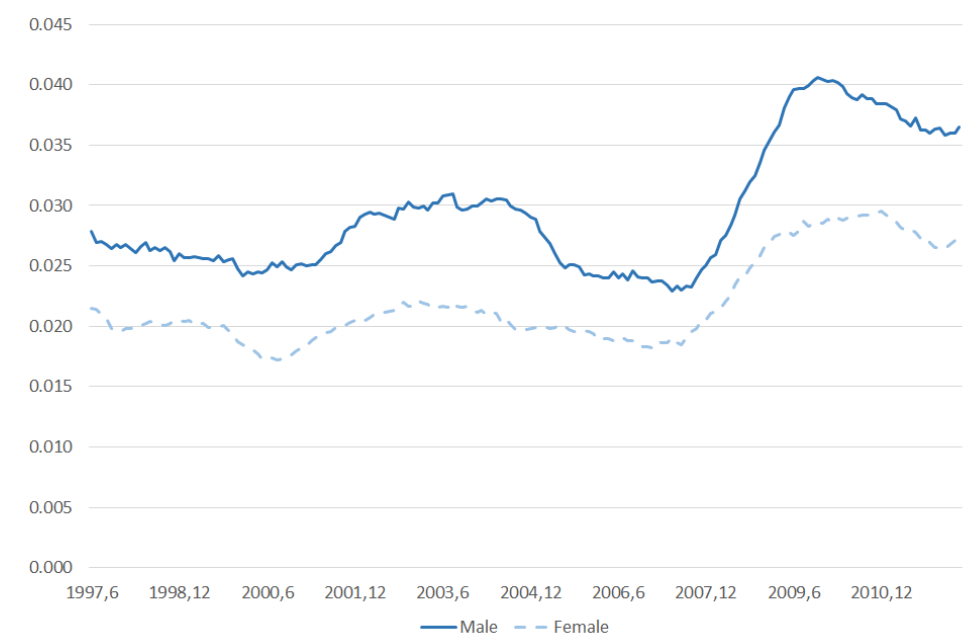

Source.- gross flows estimated using waves one \& five matched with four \& eight for each month of CPS datasets, un-weighted, and twelve month moving average.

\section{Summary}

Our main aim has been to shed light on the gender dimension of the relationship between labour market stocks and flows during the business cycle. We have built on limited evidence, which tended to focus on what happens to unemployment rates only, by looking at the relationship between the cyclical components of output and all three labour market states, with an analysis motivated by a robust output gap decomposition. Moreover, the gender dimension of labour market flows has also been overlooked in previous studies. The analysis is structured around one main issue that has emerged from the existing literature: the so-called stock-flow fallacy, whereby a lack of cyclicality in certain stocks, notably the participation rate, does not 
necessarily imply that flows between this state and others are not significantly cyclical, nor important in driving the labour market response to recessions. We assess whether there is a particular gender dimension to this stock-flow fallacy. Although male and female inactivity rates are not especially cyclical, there could be greater gender differences in the importance of flows in and out of this state over the cycle.

In both the US and UK, the response of male employment rates was at least stronger during the Great Recession, but not more generally over previous downturns. The response of the unemployment rate is not gender neutral. The male rate tends to increase more significantly than female during economic recessions. There are not substantial gender differences in the response of inactivity rates. When assessing the role fluidity has in shaping stocks, more prevalent gender differences arise than those implied by the stock-based results alone. In the past 25 years as much as a half of the variation in the US gender unemployment rate gap can be accounted for by changes in male and female rates of transition between unemployment and inactivity. For the UK these flows can also explain some of the pattern in gender differences. The majority of the difference in the unemployment rate response to the 2008 downturn can however be accounted for by a less strong response of the flows between employment and unemployment for women. But changes in the flow rates between inactivity and unemployment were also significant. For the US, these contributed similarly to the unemployment rate rise for both men and women. However, for the UK, unlike for women, the male participation flow to unemployment accounted for none of the rise in the unemployment rate. This suggests that a gender specific added worker effect was more likely to be present in the UK than in the US at the aggregate level. This is corroborated by an assessment of the heterogeneity of inactivity to unemployment transition probabilities, comparing the period of the Great Recession with the years before. Employment rate responses to the cycle also belie gender differences in the importance of the participation margin. In both countries employment is driven substantially by the procyclical entry rate from inactivity, and more so for women than for men, especially during the latest downturn.

\section{Acknowledgements}

We would like to thank participants at the 2014 European Association of Labour Economists Conference, attendees of the Centre for Analysis of Social Exclusion (CASE: LSE) and the Department of Economics RiP (University of Reading) seminar series and colleagues in the departments of economics at the University of Reading and University of Edinburgh for their comments, as well as anonymous referees. Carl Singleton would like to offer particular thanks to the Economic and Social Research Council (UK) for funding support.

\section{References}

Abowd, J. M., Zellner, A., 1985. Estimating gross labor-force flows. Journal of Business \& Economic Statistics $3(3), 254-283$.

Albanesi, S., Sahin, A., 2013. The gender unemployment gap. Staff Reports 613, Federal Reserve Bank of New York.

Attfield, C. L. F., Silverstone, B., July 1998. Okun's Law, Cointegration and Gap Variables. Journal of Macroeconomics $20(3), 625-637$.

BEA, 2014. U.S. Bureau of Economic Affaris, National Income and Product Accounts, NIPA - accessed 5/5/2014.

Blank, R. M., May 1989. Disaggregating the Effect of the Business Cycle on the Distribution of Income. Economica 56 (222), 141-63.

BLS, 2013. U.S. Bureau of Labour Statistics, Labour Force Statistics, Employed persons by occupation, sex and age, CPS - accessed 5/5/2014.

BLS, 2014. U.S. Bureau of Labour Statistics, Labour Force Statistics, CPS - accessed 5/5/2014.

BLS, 2015. U.S. Bureau of Labour Statistics, Research series on labor force status flows from the Current Population Survey - accessed 14/9/2015. 
Bryan, M. L., Longhi, S., Nov. 2013. Couples' Labour Supply Responses to Job Loss: Boom and Recession Compared. IZA Discussion Papers 7775, Institute for the Study of Labor.

Clark, K. B., Summers, L. H., July 1980. Demographic Differences in Cyclical Employment Variation. Working Paper 514, National Bureau of Economic Research.

Clarke, P. S., 1999. Methodological issues in the production and analysis of longitudinal data from the Labour Force Survey. No. 17. Office for National Statistics.

Darby, M. R., Haltiwanger, J. C., Plant, M. W., August 1986. The Ins and Outs of Unemployment: The Ins Win. Working Paper 1997, National Bureau of Economic Research.

Davies, E., 2010. Embeddable markov matrices. Electronic Journal of Probability 15, 1474-1486.

Elsby, M. W., Hobijn, B., Şahin, A., 2015. On the importance of the participation margin for labor market fluctuations. Journal of Monetary Economics 72, 64-82.

Elsby, M. W., Shin, D., Solon, G., September 2013. Wage Adjustment in the Great Recession. Working Paper 19478, National Bureau of Economic Research.

Elsby, M. W. L., Hobijn, B., Sahin, A., 2010. The Labor Market in the Great Recession. Brookings Papers on Economic Activity 41 (1), 1-69.

Elsby, M. W. L., Smith, J. C., Wadsworth, J., 2011. The role of worker flows in the dynamics and distribution of UK unemployment. Oxford Review of Economic Policy 27 (2), 338-363.

Frazis, H. J., Robison, E. L., Evans, T. D., Duff, M. A., 2005. Estimating gross flows consistent with stocks in the CPS. Monthly Labor Review 128, 3.

Fujita, S., Ramey, G., 05 2009. The Cyclicality Of Separation And Job Finding Rates. International Economic Review 50 (2), 415-430.

Gomes, P., 2012. Labour market flows: Facts from the United Kingdom. Labour Economics 19 (2), $165-175$.

Gomes, P., 2015. The importance of frequency in estimating labour market transition rates. IZA Journal of Labor Economics 4 (1), 1-10.

Gordon, R. J., 1993. The Jobless Recovery: Does It Signal a New Era of Productivity-led Growth? Brookings Papers on Economic Activity 24 (1), 271-316.

Harvey, A. C., 1989. Forecasting, structural time series models and the Kalman filter. Cambridge : Cambridge University Press, 1989.

Hodrick, R. J., Prescott, E. C., February 1997. Postwar U.S. Business Cycles: An Empirical Investigation. Journal of Money, Credit and Banking 29 (1), 1-16.

Hoynes, H. W., Miller, D. L., Shaller, J., 2012. Who Suffers During Recessions? Journal of Economic Perspectives $26(3), 27-47$.

Juhn, C., Potter, S., 2007. Is there still an added-worker effect? Staff Reports 310, Federal Reserve Bank of New York.

Kaitz, H. B., 1970. Analyzing the length of spells of unemployment. Monthly Labor Review, 11-20.

Kroft, K., Lange, F., Notowidigdo, M. J., Katz, L. F., July 2014. Long-Term Unemployment and the Great Recession: The Role of Composition, Duration Dependence, and Non-Participation. Working Paper 20273, National Bureau of Economic Research.

Lee, J., April 2000. The Robustness of Okun's Law: Evidence from OECD Countries. Journal of Macroeconomics 22 (2), 331-356.

Mankart, J., Oikonomou, R., August 2015. Household search and the aggregate labor market. Discussion Paper 26/2015, Deutsche Bundesbank, Research Centre.

Okun, A. M., 1962. Potential GNP: Its Measurement and Significance. Proceedings of the Business and Economics Statistics Section of the American Statistical Association, 98-104.

Okun, A. M., 1965. The Gap between Actual and Potential Output. In: Phelps, E. S. (Ed.), Problems of the Modern Economy. Norton, New York, pp. 287-296.

ONS, 2013. Office for National Statistics, UK, Women in the Labour Market, Labour Force Survey.

ONS, 2014a. Office for National Statistics, UK, National Accounts Aggregates, Quarterly National Accounts accessed 5/5/2014 (ABMI).

ONS, 2014b. Office for National Statistics, UK, Labour Market Statistics, Labour Force Survey - accessed $5 / 5 / 2014$.

ONS, 2015. Office for National Statistics, UK, Labour Force Survey Two-Quarter Longitudinal Dataset.

Peiro, A., Belaire-Franch, J., Gonzalo, M. T., 2012. Unemployment, cycle and gender. Journal of Macroeconomics 34 (4), 1167-1175.

Perivier, H., 2014. Men and Women during the Economic Crisis: Employment Trends in Eight European Countries. Revue de L'OFCE (133), 41-84.

Perry, G. L., 1972. Unemployment Flows in the U.S. Labor Market. Brookings Papers on Economic Activity (2), $245-278$.

Petrongolo, B., Pissarides, C. A., May 2008. The Ins and Outs of European Unemployment. American Economic Review 98 (2), 256-62.

Poterba, J. M., Summers, L. H., November 1986. Reporting Errors and Labor Market Dynamics. Econometrica $54(6), 1319-38$. 
Rubery, J., Rafferty, A., 2013. Women and recession revisited. Work, Employment \& Society 27 (3), $414-432$.

Shimer, R., 2005. The Cyclical Behavior of Equilibrium Unemployment and Vacancies. American Economic Review 95 (1), 25-49.

Shimer, R., 2012. Reassessing the Ins and Outs of Unemployment. Review of Economic Dynamics 15 (2), $127-148$. Smith, J. C., 2011. The Ins and Outs of UK Unemployment. Economic Journal 121 (552), 402-444.

Solon, G., Michaels, R., Elsby, M. W. L., January 2009. The Ins and Outs of Cyclical Unemployment. American Economic Journal: Macroeconomics 1 (1), 84-110.

Stephens, M., July 2002. Worker Displacement and the Added Worker Effect. Journal of Labor Economics 20 (3), $504-537$.

Wood, C. A., 2014. The rise in women's share of nonfarm employment during the 2007-2009 recession: a historical perspective. Monthly Labor Review 137 (4), 1. 